\title{
Sleep Deprivation And its Impact on Doctors Doing Continuous Duties
}

\author{
Dr.A.Muruganathan,M.D ${ }^{1}$, Dr.S.M.Thirunavuk Karasu,M.D² . \\ Dr.T.Ravi Kumar M.D ${ }^{3}$., Dr.N.Tamilselvan,M.S ${ }^{4}$, \\ Dr.P.Saravanan, M.D. ${ }^{5}$ DR.SOPNA JOTHI,M.D., \\ ${ }^{1}$ Emeritus Professor The Tamil Nadu Dr.Mgr Medical University \\ ${ }^{2}$ Associate Professor, Govt Theni Medical College, Theni \\ ${ }^{3}$ Prof.and HOD Of Medicine, Govt.Medical College And Esi Hospital, \\ ${ }^{4}$ Associate Prof Of Surgery Govt.Medical College And Esi Hospital, \\ ${ }^{5}$ Asst Prof Madurai Medical College,Madurai ${ }^{6}$ Asst Prof, Govt Theni Medical College, Theni
}

\begin{abstract}
Continuous duties for 24 hours ,36 hours and even 48 hours are very common in medical college, tertiary care, hospitals, icus, casualty op. many doctors are knowingly or unknowingly doing duties for years together with much difficulties, they burn themselves for their patients, but not getting adequate recognition in the form of money, awards and rewards but they get stress, burnout, diseases like hypertension obesity, diabetes and sleep disorders which result in decreased cognitive functions and adversely affect their performance

There are no studies in India regarding sleep problems among doctors
\end{abstract}

\section{Harrison text book of medicine states}

\section{Introduction}

The practice of scheduling resident physicians to more than 16 hours of duty in a day Impairs performance similar to alcoholic intoxication and is hazardous to both patient and physician who adds night shift work as carcinogen(222 page no 18 th edi ) Sleep deprivation is the condition of not having enough sleep; it can be either chronic or acute. A chronic

Sleep-restricted state can cause fatigue, daytime sleepiness, clumsiness and weight loss or weight gain. It adversely affects the brain and cognitive function.

Sleep deprivation can lead to higher risk of chronic health problems like high blood pressure, heart disease, and stroke. According to Harvard Medical School, for people with hypertension, one night without enough Sleep can cause elevated blood pressure all through the next day.

According to a study conducted by a consumer products giant, nearly 93\% Indians are sleep-deprived. The changing lifestyle and intrusion of modern gadgets have only aggravated the situation.

The study further says that $72 \%$ of Indians are waking up one to three times per night and $87 \%$ of them say lack of sleep is affecting health. On the impact on productivity, the study revels that more than $58 \%$ of Indians believe their work suffers due to lack of adequate sleep whereas $38 \%$ have witnessed a colleague falling asleep at

work.

"Food habits, lack of exercise, irregular sleep and varying working styles are basic reasons of sleep apnea. Interestingly, patients don't take sleep disorders seriously which is a cause behind many other ailments including obesity, hypertension and diabetes," said Dr Ved Prakash, adding "Patients often come for the treatment of hypertension and diabetes while upon diagnosis it is revealed that sleep apnea is one of the basic reasons for this disorder."

* 93 per cent of Indians are sleep deprived, getting less than 8 hours per night

* 58 per cent believe their work suffers due to lack of adequate sleep

* 11 per cent take leave from work because of lack of sleep

* 11 per cent have fallen asleep at work due to a poor night's sleep and 38 per cent witnessed a colleague falling asleep at work

* Lack of sleep also affects family relationships according to 19 per cent

* 87 per cent of Indians say lack of sleep affects health

* 72 per cent of Indians are waking up 1 to 3 times per night

* 15 per cent wake up over stress at work

* 33 per cent Indians snore

* Up to 14 per cent snore as loud as or louder than talking

* Only 2 per cent of Indians discuss their lack of sleep with a physician 
- Sleep Deprivation Symptoms.

- Sleepiness....

- Mood Changes. ...

- Difficulty Concentrating and Impaired Performance. ...

- Memory and Thinking Problems. ...

- Disorientation, Hallucinations and Paranoia. ...

- Somatic Complaints. ...

- Disruption of Sleep Cycle.

\section{Sleep deprivation is a form of torture.}

After two nights without sleep, the hallucinations start, and after three nights, people are having dreams while fairly awake, which is a form of psychosis.

"By the week's end, people lose their orientation in place and time - the people you're speaking to become people from your past; a window might become a view of the sea seen in your younger days. To deprive someone of sleep is to tamper with their equilibrium and their sanity.

It was a favoured torture technique of the KGBMenachem Begin, the Israeli prime minister from 1977-83, was tortured by the KGB as a young man. In his book, White Nights: The Story of a Prisoner in Russia, he wrote of losing the will to resist when deprived of sleep.

"In the head of the interrogated prisoner, a haze begins to form. His spirit is wearied to death, his legs are unsteady, and he has one sole desire: to sleep... Anyone who has experienced this desire knows that not even hunger and thirst are comparable with it."I came across prisoners who signed what they were ordered to sign, only to get what the interrogator promised them."He did not promise them their liberty; he did not promise them food to sate themselves. He promised them - if they signed - uninterrupted sleep! And, having signed, there was nothing in the world that could move them to risk again such nights and such days."

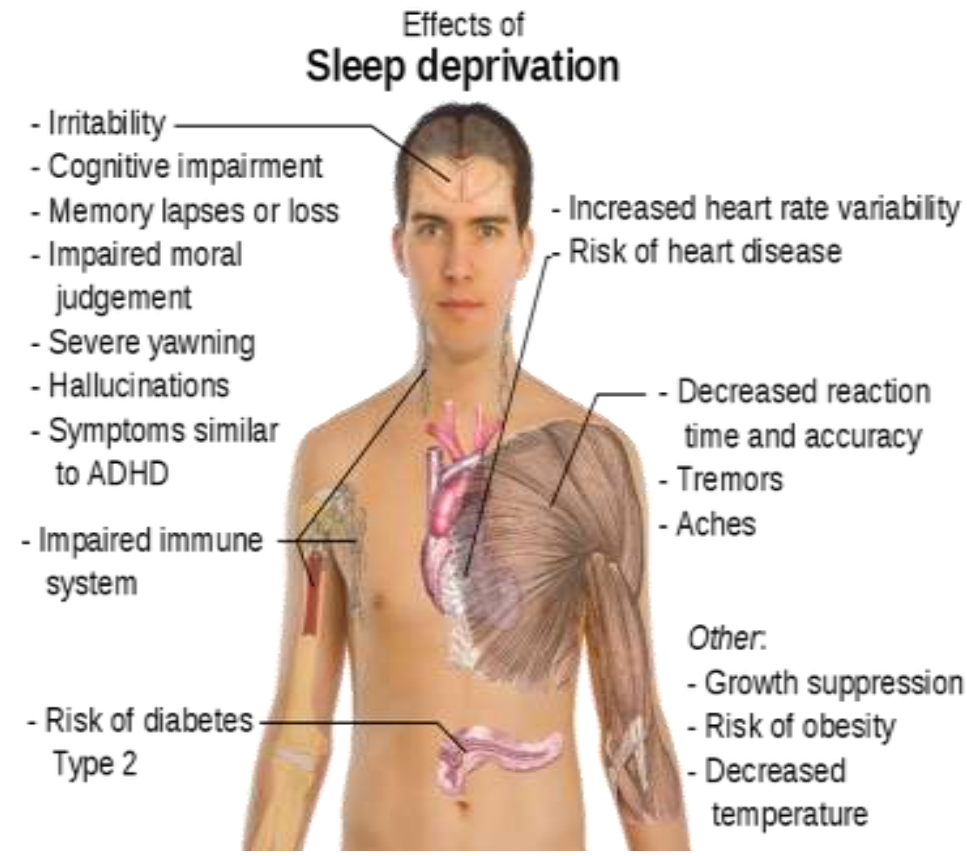

The most well-documented world record for Acute Total Sleep Deprivation is 264.4 hours held by a 17 y/o boy in San Diego.There is a rare, hereditary syndrome called Fatal familial insomnia. The first case involved a man with progressive confusion, memory loss, muscle jerking and vivid dreaming when he did sleep, followed by convulsions and death within 7 months. Studies differ as to optimum sleep time, but usually range from 6 to 8 hours. The effects of Chronic Partial Sleep Deprivation are many (as shown in the diagram above) and can be dangerous. Hence we want to conduct study to find out the problems through a standardized questionnaire and the results are analyzed, solutions are also got through it,the main aim is to bring awareness among doctors

Questionnaire Regarding Sleep Deprivation, Adverse Effects And Awareness

1.How long will u sleep in the next 12-24 hrs of your after $24 \mathrm{hrs}$ duty?

1) $<4 \mathrm{hrs} \mathrm{2)4-6hrs} \mathrm{3)} \mathrm{7-12} \mathrm{hrs} \mathrm{4)>} 12 \mathrm{hr}$

2.Do you suffer decreased cognitive abilities and judgments in making clinical decisions following sleep deprivation ?Response 1 . yes 2 . no 3 . others specify 
3. Do you frequently suffer from emotional upset(lose patience quickly, mood swings, frustration, irritability increased anxiety,) immediately following $24 \mathrm{hrs}$ sleep deprivation duty ?Response 1. yes 2 . no 3. others specify 4. Have ever met an vehicle related accident or fall with injury following sleep deprivation ?Response 1. ye 2.N 5. Do you experience micro sleep(sleep naps) following $24 \mathrm{hrs}$ sleep deprivation (That's when you're asleep for only a few seconds or a few minutes, Response 1 . yes 2. no 3. others specify

6. Do you suffer respiratory problems like the common cold, influenza and fibromyalgia following sleep deprivation ?Response 1. yes 2. no 3. others specify

7. Have frequent sleep deprivation resulted in obesity in you ?Response 1. yes 2. no 3. others specify

8. Did you ever noticed elevated blood pressure in the next day after sleep deprivation ?Response 1. yes 2 . no 3.

9. how often you are subjecting for $24 \mathrm{hrs}$ continuous duty in month?Response $1 .<2$ times 2 . 3-5 tim 3. $>5$ times

10. For how many years you have been doing such 24 hrs duty in your service?1. < 5yrs 2. 6-10yrs 3. >10-15 yrs 4. >15yrs11. How many hrs per day u sleep in your school days / Ug period

1) $<6 \mathrm{hrs}$ 2) 6-12 hrs 3) > $12 \mathrm{hrs}$ 12. How many hrs per day u sleep nowadays 1) $<6 \mathrm{hrs} \mathrm{2)} \mathrm{6-12} \mathrm{hrs} \mathrm{3)} \mathrm{>12} \mathrm{hrs}$

13. Do u become addicted to tea / coffee / substances to overcome or to manage the sleep deprivation 1)Y 2)no

14.Do you suffer from visual disturbance following $24 \mathrm{hrs} \mathrm{sleep} \mathrm{deprivation} \mathrm{duty?} 1$. yes 2 . no 3 . others specify

15. To reduce medical errors and patient harm in hospitals do you recommend stipulated working hrs for resident doctorsResponse 1. Yes 2. No 3. Others specify

16. Have $24 \mathrm{hrs}$ sleep deprivation resulted in following executive function symptoms in you, resulting in:

- Poor planning. Increased risk taking• Disorganization • Poor prioritizationFocus on short-term rewards

Response $1 .<2$ symptoms 2. 3 symptoms 3. All symptoms 4 . None

17.Do you suffer from gastrointestinal symptoms following $24 \mathrm{hrs} \mathrm{sleep} \mathrm{deprivation} \mathrm{duty?}$

Response 1. Constipation 2. Diarrhoea 3. GERD 4. Decreased appetite

18.Are you aware of an increased risk for hypertension, diabetes, obesity, heart attack and stroke in the sleepdeprived individual.Response 1. Yes 2. No 3. Others specify

19. Are you aware of sleep range for the following age groups as recommended by National Sleep

Foundation (NSF) 2015Preschoolers (3-5): 10-13 hoursSchool age children (6-13): 9-11 hours

Teenagers (14-17): 8-10 hours Younger adults (18-25): 7-9 hours Adults (26-64): 7-9 hours

Older adults (65+): 7-8 hours Response 1. Yes 2. No 3. After reading questionnaire

20.Do you think what are the solution for night duty problems ?

1) 8 hrs duty 2)posting 2 doctors in a duty 3 )shift duty 4 )any other suggestions

\begin{tabular}{|l|l|l|l|l|l|}
\hline Sl.No. & A & B & C & D & Total \\
\hline 1. & 60 & 320 & 160 & 4 & $780(96 \%)$ \\
\hline 2. & 220 & 120 & & & $340(41 \%)$ \\
\hline 3. & 420 & 36 & & & $456(56 \%)$ \\
\hline 4. & 140 & 300 & & & $440(54 \%)$ \\
\hline 5. & 360 & 80 & & & $440(54 \%)$ \\
\hline 6. & 360 & 140 & & & $500(62 \%)$ \\
\hline 7. & 120 & 160 & & & $280(35 \%)$ \\
\hline 8. & 260 & 200 & & & $460(58 \%)$ \\
\hline 9. & 320 & 240 & & & $560(69 \%)$ \\
\hline 10. & 340 & 320 & 100 & 50 & $810(100 \%)$ \\
\hline 11. & 360 & 400 & & & $760(94 \%)$ \\
\hline 12. & 340 & 160 & & & $500(62 \%)$ \\
\hline 13. & 120 & 200 & & & $320(40 \%)$ \\
\hline 14. & 460 & 40 & & & $500(62 \%)$ \\
\hline 15. & 100 & 280 & & & $380(47 \%)$ \\
\hline 16. & 60 & 260 & 50 & 50 & $420(52 \%)$ \\
\hline 17 & 420 & 40 & & & $460(58 \%)$ \\
\hline 18 & 160 & 300 & 60 & & $520(64 \%)$ \\
\hline 19 & 160 & 300 & 20 & & $480(59 \%)$ \\
\hline 20 & 180 & 40 & 280 & & $500(62 \%)$ \\
\hline
\end{tabular}

Most doctors sleep less than 4-6hrs and suffer decreased cognitive abilities and judgments in making clinical decisions. Most replied to suffer from emotional upset. 68\% (300/440) met an vehicle related accident or fall with injury following sleep deprivation. $81 \%$ (36/440) experience micro sleep(sleep naps) following $24 \mathrm{hrs}$ sleep deprivation 72\%(360/500) suffer respiratory problems like the common cold, influenza and fibromyalgia.92\% (460/500) suffer from visual disturbance following 24hrs sleep deprivation.92\% (420/460) suffer from some form of gastrointestinal symptoms following 24hrs sleep deprivation.62\% (300/480) were not aware of recommended sleep range. Most doctor favor shift duty to circumvent continuous $24 \mathrm{hrs}$ duty.Deprivation of sleep is distressing for the subjects with evidence showing raised stress hormones which may suppress memory consolidation.[1]. 65\% (220/340) in our study suffered decreased cognitive abilities and judgments in 
making clinical decisions following sleep deprivation. Chronic sleep restriction to about $5 \mathrm{~h}$ per night appears to produce even greater decrements in psychomotor vigilance performance, but these declines eventually level off at a substantially reduced level; further restriction toless than about $4 \mathrm{~h}$ nightly appears to lead to continued degradation in vigilance performance[2,3] According to Orzel-Gryglewska (2010), the most common causes of sleep deprivation are associated with lifestyle and work-related factors. College students in particular are faced with countless social and emotional adjustments at the beginning of each school year. Adjustments such as new living conditions, roommates, academic expectations, and jobs can be taxing on college students (Liguori, Schuna, \& Mozumdar, 2011). Students are often required to find a balance between schoolwork, social activities, and careers. In many cases, sleep is sacrificed for other activities. A study conducted by Pace-Schott etal. (2009) suggested that most university students accumulate sleep debt over time[4]. The negative effects of a lack of sleep can bedetrimental to an individual's health and body. Studies show that sleep deprivation has been linked to both mental and physical complications. A lack of sleep can negatively affect mood, performance, and overall health (Shulan, I-Chen, \& Ling-Ling, 2007) [4]. sleep deprivation can lead to an elevated risk of high blood pressure and heart attack (Marzano et al., 2010). Individuals may not even know the damage that is being done to these internal systems as a result of sleep deprivation. According to AlDabal and BaHammam (2011), sleep is essential for certain bodily functions such as learning, cellular repair, and memory processing. Without sleep, these processes do notfunction properlyConclusion; From the study, it is clear the effects their sleep deprivation is deletrious on memory, problem solving, and critical thinking skills, gastro intestional upset such as indigestion and GERD, prone for accidents .In order to avoid the use of harmful sleeping medications it is advisable to make lifestyle adjustments that aid in minimizing sleep deprivation. One adjustment recommended is to practice daily relaxation technique such as meditation. Such techniques allow individuals torelax both the mind and body. This is an excellent way to reduce stress and encourage better sleeping habits. Alcohol and caffeine are also substances that should be avoided before sleep and avoid watching computers, televisions and mobile phones .References

1. Born J, Fehm HL. The neuroendocrine recovery function of sleep. Noise Health. 2000;2(7):2538Patterns of performance degradation and restoration during sleep restriction and subsequent recovery: a sleep

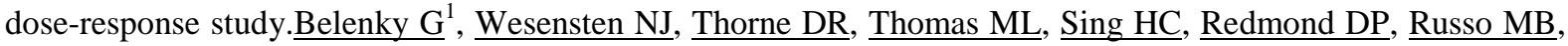
Balkin TJ.

2. . Effects of sleep deprivation on cognition William D.S. Killgore* Neuroimaging Center, McLean Hospital, Harvard Medical School, Belmont, MA, USA

3. The Effects of Sleep Deprivation on the Body Whitney L. Harrison Southern Utah UniversityChokroverty, S. S. (2010). Overviewof sleep and sleep disorders. India Goldich, Y., Barkana, Y., Pras, E., Zadok, D., Hartstein, M., \& Morad, Y. (2010). The

effects of sleep deprivation on oculomotor responses. Current Eye Research, 35(12),

1135-1141. doi:10.3109/02713683.2010.507902

4. Liguori, G., Schuna, J., \& Mozumdar, A. (2011). Semester long changes in sleep

duration for college students. College Student Journal, 45(3), 481-492.

Marzano, C., Ferrara, M., Curcio, G., \& Gennaro, L. (2010). The effects of sleep deprivation in humans: Topographical electroencephalogramchanges in non-rapid eye movement (NREM) sleep versus REM sleep. Journal of Sleep Research, 19(2), 260-268. doi: 10.1111/j.1365-2869.2009.00776.x

5. Orzel-Gryglewska, J. (2010). Consequences of sleep deprivation. International Journal of Occupational Medicine and Environmental Health, 23(1), 95-114.

doi:10.2478/v10001-010-0004-9

6. Pace-Schott, E. F., Hutcherson, C. A., Bemporad, B., Morgan, A., Kumar, A., Hobson, J., \& Stickgold, R. (2009). Failure to find executive function deficits following one night's total sleep deprivation inuniversity students under naturalistic conditions. Behavioral Sleep Medicine, 7(3), 136-163. doi:10.1080/15402000902976671

7. Shulan, H., I-Chen, C., \& Ling-Ling, T. (2007). Immediate error correction process following sleep deprivation. Journal of Sleep Research, 16(2), 137-147. 